\title{
Efeitos de uma História de Reforço Contínuo e de Conseqüências Sociais Sobre o Seguir Regras
}

\author{
Effects of a Continuous History of Reinforcement \\ and Social Consequences on Rule Following
}

\author{
Karla Maria Costa Monteles, Carla Cristina Paiva Paracampo* \\ \& Luiz Carlos de Albuquerque \\ Universidade Federal do Pará, Belém, Brasil
}

\begin{abstract}
Resumo
Com o objetivo de investigar os efeitos de variáveis envolvidas no seguir regras, 18 crianças foram expostas a um procedimento de escolha segundo o modelo. A tarefa era tocar um de dois estímulos de comparação na presença de um estímulo contextual. As respostas corretas eram reforçadas com fichas. A Fase 1 era iniciada com a instrução mínima; a Fase 2, com a instrução correspondente às contingências e as Fases 3 e 4, com mudança nas contingências. As três condições diferiam nas Fases 1 e 3. Na Fase 1 da Condição 1 nenhuma resposta era reforçada e na Fase 1 das Condições 2 e 3, havia reforço diferencial das respostas corretas. Na Fase 3 das três condições, a manutenção do seguir regra não produzia ficha, mas produzia elogio na Condição 3. O seguir regra foi mantido nas Condições 1 e 3 e foi abandonado na Condição 2. Discute-se algumas explicações para a manutenção do seguir regras.

Palavras-chave: Controle por regras; controle por história de reforço; controle por consequiências sociais; procedimento de escolha segundo o modelo; crianças.

Abstract

In order to investigate the effects of variables involved in rule following, 18 children were exposed to a matching-to-sample procedure. Each child touched one of two comparison stimuli in the presence of a contextual stimulus. Correct responses were reinforced with tokens. Phase 1 began with minimal instruction, Phase 2 with a contingency-correspondent rule, and Phases 3 and 4 with a change in the contingencies. The three experimental conditions differed in Phases 1 and 3. In Phase 1 of Condition 1, no response was reinforced, and in Phase 1 of Conditions 2 and 3, there was differential reinforcement of the correct responses. In Phase 3 of the three conditions, the maintenance of rule following was not rewarded with tokens; instead praise was delivered in Condition 3. Rule following was maintained in Conditions 1 and 3, but left out in Condition 2. Some explanations are provided for the maintenance of rule following behavior.

Keywords: Control by rules; control by reinforcement history; control by social consequences; matching-to sample; children.
\end{abstract}

De acordo com Skinner (1969), regras são estímulos especificadores de contingências que exercem controle como estímulos discriminativos, fazendo parte de um conjunto de contingências de reforço. Ou seja, são estímulos antecedentes verbais que podem especificar o comportamento a ser emitido, as condições sob as quais ele deve ser emitido, e suas prováveis conseqüências. Por esta definição ${ }^{1}$, instruções, avisos, conselhos, ordens, leis, seriam exemplos particulares de regras, uma vez que todos des-

"Endereço para correspondência: Rua Oliveira Belo, 238/ 1702, Umarizal, Belém, PA, 66.050-380. Fone: (91) 3223 8995. E-mail: cparacampo@gmail.com

Este trabalho foi baseado nos dados da dissertação de mestrado do primeiro autor apresentada em 2004 no Programa de Pós-Graduação em Teoria e Pesquisa do Comportamento/UFPA e realizada sob orientação do segundo e coorientação do terceiro autor. O trabalho foi realizado com o auxílio financeiro da CAPES, em forma de bolsa concedida ao primeiro autor, e do $\mathrm{CNPq}$

${ }^{1}$ No presente estudo o termo "regra" está sendo usado em situações mais amplas e o termo "instrução" está sendo usado em situações mais restritas, como nas descrições dos procedimentos e resultados de pesquisas. crevem, explicita ou implicitamente, contingências e, assim, podem funcionar como estímulos discriminativos.

Tanto regras quanto contingências podem estabelecer comportamentos novos. Diferente das contingências de reforço, no entanto, regras podem estabelecer comportamentos novos, antes mesmo de estes comportamentos manterem contato com as suas conseqüências imediatas (L. C. Albuquerque, de Souza, Matos, \& Paracampo, 2003). Deste modo, regras podem tornar a aquisição do comportamento mais rápida e permitir que comportamentos complexos sejam adquiridos, principalmente em situações em que as contingências naturais são pouco claras, atuam apenas a longo prazo, são ineficazes, ou não poderiam ser contatadas naturalmente (Catania, 1998; Malott, 1989; Skinner, 1969). Um problema, no entanto, é que quando as contingências mudam, e não as regras, o comportamento estabelecido por regras tende a não mudar acompanhando as mudanças nas contingências de reforço (Skinner, 1969).

Um dos primeiros estudos a testar essa predição de Skinner (1969) foi o realizado por Shimoff, Catania, e 
Matthews (1981). Estes autores expuseram estudantes universitários a um esquema DRL $3 \mathrm{~s}$ superposto a um esquema RI 15 s. Os participantes foram distribuídos em dois grupos. O Grupo 1 era instruído a pressionar um botão devagar. O Grupo 2 não era exposto a tal instrução. Para os dois grupos, após 10 min de sessão, as contingências eram alteradas com a retirada do esquema DRL. Quando as contingências foram alteradas, apenas 4 dos 10 participantes do Grupo 1 (responder estabelecido por instrução) e 6 dos 7 participantes do Grupo 2 (responder estabelecido por modelagem), passaram a responder sob o controle do esquema RI $15 \mathrm{~s}$. Nesta mesma linha de investigação, Paracampo, de Souza, Matos, e L. C. Albuquerque (2001) expuseram crianças a um procedimento de controle contextual de escolha segundo o modelo. As condições diferiam apenas quanto à forma de estabelecimento do comportamento no início da Fase 1 . Na Fase 1 da Condição 1, o comportamento era estabelecido por reforço diferencial, enquanto que na Fase 1 da Condição 2, era estabelecido por instrução. Nas duas condições, as contingências em vigor na Fase 1 eram revertidas na Fase 2 e restabelecidas na Fase 3. Na Condição 1 (responder estabelecido por reforço diferencial), o desempenho dos 5 participantes, que aprenderam a executar a tarefa de discriminação condicional, mudou acompanhando as mudanças nas contingências de reforço. Inversamente, na Condição 2 (responder estabelecido por instrução), o desempenho dos 6 participantes não mudou acompanhando as mudanças nas contingências de reforço.

Estes estudos (Paracampo et al., 2001; Shimoff et al., 1981) têm mostrado que o responder inicialmente estabelecido por regras é menos provável de mudar acompanhando mudanças nas contingências de reforço programadas do que o responder estabelecido por modelagem ou por reforço diferencial. Esta característica do comportamento controlado por regras tem sido chamada de insensibilidade às mudanças nas contingências (Matthews, Shimoff, \& Catania, 1977; Shimoff et al., 1981).

Alguns estudos, no entanto, têm mostrado que o comportamento de seguir regras nem sempre se apresenta como insensível às contingências de reforço; ou seja, tem sido mostrado que a manutenção deste comportamento depende de algumas condições, como por exemplo, do tipo de conseqüência contatada (N. M. A. Albuquerque, Paracampo, \& L. C. Albuquerque, 2004; Galizio, 1979; Hayes, Brownstein, Zettle, Rosenfarb, \& Korn, 1986; Paracampo \& Albuquerque, 2004; Shimoff et al., 1981) e de variáveis históricas (L. C. Albuquerque et al., 2003; L. C. Albuquerque, Reis, \& Paracampo, 2006; LeFrancois, Chase, \& Joyce, 1988; Paracampo et al., 2001; Santos, Paracampo, \& L. C. Albuquerque, 2004).

Iniciando com a análise das conseqüências do comportamento controlado por regras, Galizio (1979) expôs 4 universitários a um esquema múltiplo com quatro componentes: FI 10 s, FI 30 s, FI 60 s e não perda. A tarefa era girar uma alavanca, o que evitava a perda de pontos de acordo com o esquema FI em vigor. Na Fase 1, a apresentação de instrução que correspondia ao esquema em efeito foi acompanhada pela ocorrência de responder diferenciado nos quatro componentes. Na Fase 2 , quando as contingências foram alteradas para uma condição de não perda em todos os componentes, não foi observada mudança no desempenho dos participantes. Na Fase 3, quando as contingências foram novamente alteradas para um esquema FI $10 \mathrm{~s}$ em todos os componentes e o seguimento de instrução passou a produzir perda de pontos trocáveis por dinheiro, todos os participantes deixaram de seguir a instrução e passaram a responder de acordo com as contingências.

Galizio (1979) propôs que o comportamento de seguir regras pode ser mantido, após mudanças nas contingências, quando não mantém contato com a discrepância regra / contingências (como ocorreu na Fase 2). Quando o seguimento de regras mantém contato com essa discrepância (como ocorreu na Fase 3), é provável que ele mude acompanhando as mudanças nas contingências. Deste modo, Galizio concluiu que o seguimento de regras é determinado por suas conseqüências.

Outros estudos (L. C. Albuquerque et al., 2003; Hayes et al., 1986; Shimoff et al., 1981), entretanto, têm sugerido que manter contato com a discrepância entre as conseqüências descritas na regra e as conseqüências produzidas pelo comportamento de seguir regra não é uma condição suficiente para impedir que o comportamento de seguir regra discrepante das contingências de reforço seja mantido. Por exemplo, L. C. Albuquerque et al. (2003), no Experimento 1 expuseram 4 universitários a um procedimento de escolha segundo o modelo, com três estímulos de comparação; a tarefa consistia em apontar para cada um dos estímulos de comparação, em seqüência. Na Fase 1 (linha de base) nenhuma seqüência era reforçada ou instruída. Cada uma das Fases 2 e 4 era iniciada com a instrução discrepante das contingências especificando uma seqüência incorreta. A Fase 3 era iniciada com a instrução correspondente às contingências especificando a seqüência correta. Durante as Fases 2, 3 e 4 havia apenas uma seqüência correta, que era reforçada em esquema FR 4. Todos os participantes apresentaram um desempenho variável na Fase 1 e todos seguiram as instruções nas demais fases.

Esses resultados são consistentes com resultados de estudos anteriores (por exemplo, Kaufman, Baron, \& Koop, 1966; Weiner, 1970) e sugerem que o comportamento de seguir regra pode ser mantido mesmo quando produz conseqüências que contradizem a regra. Sugerem ainda que outras variáveis, fora da situação experimental, podem ser responsáveis pela manutenção do comportamento de seguir regras (L. C. Albuquerque et al., 2003). É possível que neste estudo o seguimento da regra discrepante tenha sido mantido, devido a uma história de reforço social para o responder de acordo com regras (Hayes et al., 1986; Hayes, Zettle \& Rosenfarb, 1989; Zettle \& Hayes, 1982). Por esta visão, o comportamento de seguir regras pode estar sob o controle de duas fontes de variáveis distintas: as conseqüências mediadas socialmente para o responder de acordo com regras e as conseqüências 
atuais que seguem o comportamento de seguir regras (Zettle \& Hayes, 1982). Assim, a insensibilidade do seguimento de regras às contingências tenderia a ocorrer quando, em uma determinada situação, prevalecesse o controle pelas conseqüências mediadas socialmente para o responder de acordo com regras (Hayes et al., 1986).

Passando agora a analisar as variáveis históricas que podem interferir no comportamento de seguir regras, tem sido proposto que o seguimento de regras discrepantes das contingências de reforço tem maior probabilidade de ser mantido quando as contingências são fracas do que quando são fortes (Cerutti, 1989). Operacionalizando essa sugestão, Torgrud e Holborn (1990) propuseram, após uma análise de alguns estudos dessa linha de pesquisa, que o seguimento de regras discrepantes das contingências tem maior probabilidade de ser mantido quando não se demonstra controle pelas contingências de reforço do que quando tal controle é demonstrado, antes da apresentação de uma regra ao ouvinte. Torgrud e Holborn, no entanto, não compararam o controle pelas contingências com o controle por regras, quando procuraram testar essa proposição no Experimento 1 deste estudo. Ao invés, compararam o controle exercido por dois conjuntos de contingências. Ou seja, neste experimento foi comparado o controle pelas contingências de reforço programadas para as respostas não-verbais (no caso, pressão à chave em um esquema múltiplo) com o controle pelas contingências de reforço programadas para as respostas verbais (no caso, descrições das taxas de pressões à chave), quando o controle pelas contingências programadas para as respostas não-verbais era demonstrado antes das respostas verbais serem solicitadas aos participantes. Os autores relataram que as contingências de reforço programadas para as respostas não-verbais e as contingências de reforço programadas para as descrições verbais controlaram suas respectivas classes de respostas sem interferência mútua.

Um dos estudos que investigou o controle por regras quando se demonstra controle pelas contingências antes apresentação da regra foi o Experimento 2 realizado por L. C. Albuquerque et al. (2003). Neste experimento, oito universitários foram expostos a um procedimento de escolha segundo o modelo que diferiu do usado no Experimento 1, previamente descrito, em apenas dois aspectos: no Experimento 2 procurou-se demonstrar controle pelas contingências de reforço na Fase 1, antes da introdução das instruções nas Fases 2, 3 e 4, e a emissão do comportamento modelado e mantido em esquema FR 4 na Fase 1 continuava sendo reforçada nas demais fases subseqüentes. A seqüência correta foi modelada em 6 participantes na Fase 1. Destes, 4 seguiram e 2 deixaram de seguir tanto a instrução correspondente quanto a instrução discrepante das contingências nas demais fases subseqüentes.

De acordo com L. C. Albuquerque et al. (2003), os resultados dos 4 participantes que seguiram regras neste experimento sugerem que regras podem ser seguidas mesmo quando as contingências de reforço que contradizem a regra são fortes, isto é, mesmo quando se demonstra controle por estas contingências antes de o ouvinte ser exposto à regra. Assim, estabelecer por contingências um comportamento alternativo ao comportamento especificado por uma regra discrepante das contingências de reforço, antes da apresentação da regra ao ouvinte, não é uma condição, por si só, suficiente para impedir que uma regra discrepante dessas contingências exerça controle sobre o comportamento por ela especificado.

Dando continuidade a essa linha de investigação, L. C. Albuquerque et al. (2006) expuseram 16 universitários a um procedimento de escolha segundo o modelo que diferiu do usado no estudo anterior, porque se utilizou um esquema de reforço contínuo, e não um esquema FR 4. Neste estudo foram realizados dois experimentos. No Experimento 1 não foi demonstrado controle pelas contingências de reforço antes da introdução das instruções, enquanto no Experimento 2 tal controle foi demonstrado. Todos os 8 participantes do Experimento 1 seguiram tanto a instrução correspondente quanto a instrução discrepante das contingências e 7 dos 8 participantes do Experimento 2 abandonaram o seguimento da instrução discrepante e passaram a responder de acordo com suas histórias experimentais.

De acordo com L. C. Albuquerque et al. (2006), esses resultados, quando comparados com os resultados obtidos no estudo anterior (L. C. Albuquerque et al., 2003), sugerem que, quando o comportamento de seguir regras discrepantes das contingências de reforço não é precedido por uma história de controle pelas contingências, ele tende a ser mantido, independentemente de o esquema de reforço programado para reforçar o comportamento de seguir ou o de não seguir a regra ser um esquema de reforço contínuo ou um esquema de reforço intermitente. Contudo, quando o comportamento de seguir regra é precedido por uma história de controle pelas contingências de reforço, é mais provável que o comportamento de seguir regras discrepantes seja mantido quando, antes de ser exposto à regra, o ouvinte é exposto a uma história de controle por esquema de reforço intermitente do que quando é exposto a uma história de controle por esquema de reforço contínuo. É possível que essas diferenças de resultados tenham ocorrido, porque no Experimento 2 do estudo de L. C. Albuquerque et al. (2006) as contingências de reforço programadas para o comportamento alternativo ao especificado pela regra discrepante eram mais simples e exigiam menor custo de respostas para serem cumpridas do que as contingências programadas para este comportamento no estudo anterior. Ou seja, para o nãoseguimento da regra discrepante ser reforçado, no Experimento 2 do estudo de L. C. Albuquerque et al. (2006), o participante tinha que emitir apenas uma determinada seqüência de respostas. Já no Experimento 2 do estudo de L. C. Albuquerque et al. (2003), o participante tinha que emitir uma determinada seqüência de respostas quatro vezes consecutivas e erros ou a não emissão consecutiva de uma mesma seqüência correta, reiniciavam a razão fixa para obtenção de um ponto (L. C. Albuquerque, Matos, de Souza \& Paracampo, 2004; L. C. Albuquerque et al., 2006). 
Em síntese, esta análise sugere que a probabilidade futura do comportamento de seguir regras vir a ocorrer poderia ser alterada manipulando-se tanto as consequiências deste comportamento quanto às condições que o antecedem. Assim, deveria ser esperado que o comportamento de seguir regra que não produz as conseqüências especificadas na regra fosse mantido, caso fosse seguido de reforço social, e deveria ser esperado que este comportamento deixasse de ocorrer, caso o comportamento alternativo ao especificado pela regra fosse estabelecido e mantido em esquema de reforço contínuo antes da introdução da regra. Contudo, não está claro o que aconteceria, se o comportamento de seguir regra fosse exposto a estas duas condições, concorrentemente, uma vez que nenhum dos estudos comentados até o momento investigou esta possibilidade.

Em outras palavras, tomando o estudo de Paracampo et al. (2001) como parâmetro, o que aconteceria se, antes da apresentação de uma regra correspondente às contingências, fosse demonstrado controle por um esquema de reforço contínuo sobre o comportamento alternativo ao especificado pela regra e, após a mudança nas contingências, a manutenção do comportamento de seguir regra deixasse de produzir as consequiências especificadas na regra (fichas trocáveis por brinquedos) e passasse a produzir reforço social ("Muito bem") e a emissão do comportamento alternativo ao especificado pela regra fosse reforçada com fichas trocáveis por brinquedos? Neste caso, prevaleceria o controle pela história de reforço ou controle pelas conseqüências sociais sobre o comportamento de seguir regras? Se, após a mudança nas contingências de reforço programadas, prevalecesse o controle pela história de reforço, deveria ser esperado que o comportamento de seguir regra deixasse de ocorrer; se prevalecesse o controle pelas conseqüências sociais, deveria ser esperado que o comportamento de seguir regra fosse mantido.

O presente estudo teve como objetivo avaliar a competição entre o controle por uma história experimental de reforço contínuo e o controle pelas conseqüências sociais sobre o comportamento de seguir regras que, após a mudança nas contingências de reforço programadas, tornam-se discrepantes dessas contingências. Mais especificamente, este estudo pretendeu verificar se a construção de uma história de reforço contínuo, antes de o ouvinte ser expos-to à regra correspondente, tornaria o seguimento subseqüente dessa regra sensível à mudança nas contingências de reforço programadas. Isto quando, após a mudança nas contingências, a manutenção do comportamento de seguir regra for seguida de reforço social em uma condição e, em outra condição, não produzir qualquer reforço diferencial.

\section{Método}

\section{Participantes}

Participaram do estudo 10 meninos (P11, P13, P21, P22, P24, P25, P27, P32, P34, e P37) e 8 meninas (P12, P14, P23, P26, P31, P33, P35 e P36), com idades variando entre 7 e 9 anos, cursando a $1^{\mathrm{a}}$ ou $2^{\mathrm{a}}$ série do Ensino Fundamental em uma escola particular. De cada turma foram escolhidas, pela professora, no máximo três crianças. As crianças de uma mesma turma sempre foram atribuídas a condições experimentais diferentes. Todas as crianças foram previamente autorizadas pelos responsáveis a participar da pesquisa através de um formulário de consentimento assinado pelos mesmos.

\section{Material}

Foi utilizada uma mesa retangular de madeira pintada de branco, cujo tampo tinha uma abertura de 49,5 x 49,5 $\mathrm{cm}$, coberta por uma placa de acrílico leitoso, sob a qual ficavam quatro lâmpadas fluorescentes de 20 watts, duas de cor vermelha e duas de cor amarela. Separando o experimentador do participante, sobre a mesa, havia um anteparo de madeira de $14 \mathrm{~cm}$ de altura e $69,5 \mathrm{~cm}$ de comprimento subdividido em três compartimentos iguais. Dentro destes compartimentos ficavam os arranjos de estímulos previamente preparados. Em frente ao terceiro compartimento, à direita do experimentador, ficava um conjunto de interruptores para o controle das lâmpadas fluorescentes.

Foram utilizados como estímulos discriminativos e condicionais 45 desenhos coloridos de objetos conhecidos das crianças (por exemplo, uma bola, uma lua, uma meia). Estes desenhos de 5 x $5 \mathrm{~cm}$ cada, eram impressos em cartões de papelão que eram colados em folhas de papel cartão de $14 \times 14 \mathrm{~cm}$, de maneira a formar 30 diferentes arranjos de estímulos. Cada arranjo de estímulos continha três cartões com desenhos; dois desenhos eram sempre iguais entre si e o terceiro era diferente. Um cartão contendo um dos desenhos iguais era colado no topo da folha (estímulo modelo) e os outros dois mais abaixo e lado a lado (estímulos de comparação). A combinação dos estímulos era aleatória, assim como a ordem de apresentação dos 30 arranjos. Como estímulos contextuais foram utilizadas lâmpadas coloridas acesas e como estímulos reforçadores, fichas pretas que poderiam ser trocadas por brinquedos e guloseimas. Foram utilizados dois copos descartáveis para guardar as fichas. Os copos ficavam sobre a mesa, um próximo ao experimentador e o outro próximo ao participante.

O desempenho dos participantes era registrado tanto pelo experimentador quanto por um observador (que ficava sentado atrás do participante) em um protocolo de registro previamente preparado e era também gravado em vídeo para análises posteriores.

$\mathrm{O}$ experimento foi realizado em uma sala da escola. $\mathrm{Na}$ sala, além da mesa experimental, havia uma mesa, visível ao participante, sobre a qual ficavam expostos diversos brinquedos e guloseimas. Em cada brinquedo e guloseima estava afixada uma etiqueta de papel com um número impresso, indicando o total de fichas que cada brinquedo e guloseima valia. Uma filmadora de vídeo estava instalada dentro da sala a uma distância de um metro da mesa experimental, com o objetivo de filmar as respostas dos participantes. 


\section{Procedimento}

Após ser convidada pela professora a participar de um jogo, a criança era conduzida à sala experimental pelo experimentador. Ao entrar na sala, o experimentador mostrava a mesa com brinquedos e guloseimas à criança e apresentava, oralmente, as seguintes instruções iniciais: "Eu te trouxe aqui para nós brincarmos de um jogo. No jogo nós temos esta lojinha com vários brinquedos. Estes brinquedos podem ser comprados com fichas como estas aqui" (o experimentador mostrava cinco fichas ao participante). "Por exemplo, este carrinho vale 10 fichas, esta boneca vale 20 fichas. Durante o jogo você poderá ganhar muitas fichas, e no final do jogo você poderá vir aqui na lojinha e comprar brinquedos com suas fichas. Quanto mais fichas você ganhar, mais brinquedos você poderá comprar. Entendeu?" (esta instrução era repetida mais uma vez). Em seguida, o experimentador dizia: «Agora eu vou te mostrar como se compra na lojinha. Eu vou te dar cinco fichas para você fazer uma compra na lojinha. Vamos ver o que você pode comprar com cinco fichas?" Após o participante fazer a compra o experimentador dizia: "Agora vamos para aquela mesa que eu vou te explicar como é o jogo". Participante e experimentador se dirigiam à mesa experimental, com o participante levando o brinquedo e/ou a guloseima que comprou, e era dado o início à sessão experimental.

No início da sessão experimental, que durava aproximadamente 40 minutos, participante e experimentador ficavam sentados à mesa experimental, frente a frente. $\mathrm{O}$ experimentador apresentava oralmente ao participante uma instrução (descrita a seguir) e, logo após passava a apresentar os arranjos de estímulos. Em cada tentativa, um arranjo constituído de um estímulo modelo e dois de comparação era apresentado ao participante e em seguida uma das lâmpadas era acesa. Na presença desses estímulos o participante deveria tocar com o dedo apenas um dos estímulos de comparação. Caso a resposta estivesse de acordo com as contingências de reforço programadas (resposta correta), uma ficha era colocada no copo próximo ao participante, a lâmpada era apagada e o arranjo retirado. Caso a resposta fosse considerada incorreta, a lâmpada era apagada e o arranjo retirado, sem a apresentação da ficha. Cada arranjo ficava disponível para o participante por $5 \mathrm{~s}$ no máximo. Imediatamente após o participante emitir a resposta de tocar um dos estímulos de comparação, ou se o participante não emitisse a resposta requisitada de tocar, passados esses $5 \mathrm{~s}$ um novo arranjo era apresentado e outra lâmpada era acesa, iniciando uma nova tentativa. $\mathrm{O}$ intervalo entre tentativas era o tempo gasto pelo experimentador nas tarefas de tirar um arranjo de estímulos e apresentar outro. Caso em uma mesma tentativa o participante apontasse para um estímulo de comparação e em seguida apontasse para o outro, o experimentador considerava apenas a segunda resposta de tocar e dizia ao participante, referindo-se ao estímulo de comparação: "Você deve tocar apenas para um dos filhos quando uma luz for acesa".

Os participantes foram distribuídos em três condições experimentais, como indicado na Tabela 1. A Condição 1 foi realizada com 4 participantes e cada uma das Condições 2 e 3, com 7 participantes. Cada condição era constituída de quatro fases. Nas três condições, a Fase 1 era iniciada com a apresentação da instrução mínima, a Fase 2, com a apresentação da instrução correspondente às contingências programadas e o início das Fases 3 e 4 era marcado apenas pela mudança, não sinalizada, nas contingências de reforço programadas.

Tabela 1

Respostas Reforçadas com Fichas nas Quatro Fases das Três Condições Experimentais

\begin{tabular}{clllll}
\hline \multirow{2}{*}{ Condições } & & \multicolumn{4}{c}{ Respostas Reforçadas } \\
\cline { 3 - 5 } & Luzes & Fase 1 & Fase 2 & Fase 3 & Fase 4 \\
\hline \multirow{2}{*}{1} & Vermelha & Nenhuma & Igual & Diferente & Igual \\
& Amarela & Nenhuma & Diferente & Igual & Diferente \\
\hline \multirow{2}{*}{2} & Vermelha & Diferente & Igual & Diferente & Igual \\
& Amarela & Igual & Diferente & Igual & Diferente \\
\hline \multirow{2}{*}{3} & Vermelha & Diferente & Igual & Diferente & Igual \\
& Amarela & Igual & Diferente & Igual & Diferente \\
\hline
\end{tabular}

Nota. A Condição 1 foi realizada com quatro participantes e cada uma das Condições 2 e 3 , com sete. A palavra igual representa a resposta de escolha do estímulo de comparação igual ao modelo. A palavra diferente representa a resposta de escolha do estímulo de comparação diferente do modelo. Nas três condições, a Fase 1 era iniciada com a instrução mínima e a Fase 2 com a apresentação da instrução correspondente às contingências em vigor nesta fase. As transições da Fase 2 para a Fase 3 e desta para a Fase 4 não eram sinalizadas. Diferente da Fase 3 das outras duas condições, na Fase 3 da Condição 3 as respostas de escolher o estímulo de comparação igual ao modelo na presença da luz vermelha e de escolher o estímulo de comparação diferente do modelo na presença da luz amarela, produziam reforço social.

No início da Fase 1 da Condição 1 a instrução mínima era apresentada como se segue. O experimentador apresentava ao participante um arranjo de estímulos, apontava para o cartão modelo e dizia: "Este é o cartão-mãe. Toque com o dedo o cartão-mãe". Após o participante tocar com o dedo o cartão-mãe, o experimentador apontava para os dois cartões de comparação e dizia: "Este são os cartõesfilhos. Toque com o dedo os cartões-filhos". Após o participan- 
te tocar com o dedo os cartões-filhos, o experimentador dizia: "Durante o jogo você deve tocar com o dedo um dos filhos e descobrir qual filho vai com a mãe quando a mesa ficar desta cor (o experimentador acendia a luz vermelha ou a luz amarela) ou desta cor" (o experimentador acendia a outra luz). "Mas lembre, você deve tocar um dos filhos só depois que a mesa ficar desta cor (o experimentador acendia novamente a luz vermelha ou a luz amarela) ou desta cor" (o experimentador acendia a outra luz). A instrução mínima era apresentada duas vezes ao participante. Após a apresentação desta instrução, o experimentador informava ao participante que não poderia mais conversar com ele durante o jogo.

Diferente da Condição 1, a instrução mínima apresentada nas Condições 2 e 3 especificava também que os participantes poderiam ganhar fichas. Deste modo, na Fase 1 dessas duas últimas condições o experimentador dizia ao participante: "O objetivo do jogo é você ganhar muitas fichas para depois comprar brinquedos naquela lojinha. Você ganha uma ficha quando eu tiro aqui do meu copinho e coloco no seu" (no presente experimento, todas as vezes que esta frase era dita, o experimentador tirava uma ficha do seu copo e a colocava no copo do participante). Em seguida, o experimentador apresentava ao participante um arranjo de estímulos, apontava para o cartão modelo e dizia: "Este é o cartão-mãe. Toque com o dedo o cartão-mãe”. Após o participante tocar com o dedo o cartão-mãe o experimentador apontava para os dois cartões de comparação e dizia: "Este são os cartões-filhos. Toque com o dedo os cartões-filhos”. Após o participante tocar com o dedo os cartões-filhos, o experimentador dizia: "Durante o jogo a sua tarefa é descobrir como se ganha fichas. Para descobrir como se ganha fichas você deve tocar com o dedo um dos filhos e descobrir qual filho vai com a mãe quando a mesa ficar desta cor (o experimentador acendia a luz vermelha ou a luz amarela) ou desta cor" (o experimentador acendia a outra luz). "Mas lembre, você deve tocar um dos filhos só depois que a mesa ficar desta cor (o experimentador acendia novamente a luz vermelha ou a luz amarela) ou desta cor" (o experimentador acendia a outra luz). A instrução mínima era apresentada duas vezes para o participante. Após a apresentação desta instrução, o experimentador informava ao participante que não poderia mais conversar com ele durante o jogo.

Durante a Fase 1 da Condição 1 nenhuma resposta era reforçada diferencialmente com fichas. Esta fase era constituída de seis tentativas de linha de base em relação à qual eram avaliados os efeitos da introdução da instrução correspondente às contingências na Fase 2. Durante a Fase 1 das Condições 2 e 3 eram reforçadas com fichas as respostas de tocar o estímulo de comparação diferente do estímulo modelo quando a luz vermelha estivesse acesa e as respostas de tocar o estímulo de comparação igual ao modelo quando a luz amarela estivesse acesa (respostas consideradas "corretas" na Fase 1 das Condições 2 e 3). O procedimento para o estabelecimento das respostas corretas durante a Fase 1 das Condições 2 e 3 variou dependendo do desempenho de cada participante, mas, em geral, no início deste procedimento a luz vermelha era acesa até que um de dois critérios fosse atingido, o que ocorresse primeiro: (a) a emissão de 10 respostas corretas consecutivas e ou, (b) a ocorrência de 20 tentativas. Após um ou outro desses critérios ser atingido, a luz amarela passava a ficar acesa até que um de dois critérios fosse atingido, o que ocorresse primeiro: (a) a emissão de 10 respostas corretas consecutivas ou, (b) a ocorrência de 80 tentativas. Caso o critério de desempenho não fosse atingido na presença da luz amarela, a participação da criança no experimento era encerrada na Fase 1. Caso este critério de desempenho fosse atingido, o experimentador procedia de uma de duas maneiras, dependendo do desempenho do participante apresentado previamente na presença da luz vermelha. Se o critério de 10 respostas corretas consecutivas na presença da luz vermelha ainda não tivesse sido atingido, a luz vermelha era reapresentada até este critério ser alcançado. Caso o participante não atingisse esse critério até a $100^{a}$ tentativa, a sua participação no experimento também era encerrada na Fase 1. Caso o participante tivesse atingido os critérios de desempenho na presença das luzes vermelha e amarela, isto é, caso tivesse emitido 10 respostas corretas consecutivas na presença da luz vermelha e na presença da luz amarela, as luzes vermelha e amarela passavam a ser apresentadas aleatoriamente, até a emissão de 10 respostas corretas consecutivas, quando esta fase era encerrada. Caso o participante não atingisse este critério de desempenho até a $100^{a}$ tentativa, a sua participação no experimento também era encerrada na Fase 1. Portanto, só eram expostos às Fases 2, 3 e 4 os participantes que atingissem o critério de desempenho para o encerramento da Fase 1.

Nas três condições, no início da Fase 2 o experimentador apresentava ao participante a instrução correspondente às contingências da seguinte maneira: O experimentador acendia a luz vermelha e dizia: "Quando a mesa ficar vermelha, você deve tocar com o dedo o filho que é igual à mãe. A mesa está vermelha, toque com o dedo o filho que é igual à mãe". Após o participante tocar, o experimentador dizia: "Fazendo isso, você ganha uma ficha que eu tiro aqui do meu copinho e coloco no seu". Em seguida o experimentador acendia a luz amarela e dizia: "Quando a mesa ficar amarela, você deve tocar com o dedo o filho que é diferente da mãe. A mesa está amarela, toque com o dedo o filho que é diferente da mãe". Após o participante tocar, o experimentador dizia: "Fazendo isso, você ganha uma ficha que eu tiro aqui do meu copinho e coloco no seu". Esta instrução era apresentada mais uma vez ao participante. Após a apresentação desta instrução, o experimentador informava ao participante que não poderia mais conversar com ele durante o jogo.

Durante a Fase 2 das três condições, as luzes vermelha e amarela eram apresentadas aleatoriamente e eram reforçadas com fichas as respostas de tocar o estímulo de comparação igual ao modelo quando a luz vermelha estivesse acesa e as respostas de tocar o estímulo de comparação diferente do modelo quando a luz amarela estivesse acesa. Esta fase era encerrada após a emissão de 10 respostas corretas consecutivas, desde que o participante já tivesse obtido, no mínimo, 20 reforços nesta fase. A transição da 
Fase 2 para a Fase 3 não era sinalizada; era marcada apenas pela mudança nas contingências de reforço.

Durante a Fase 3 das três condições as luzes vermelha e amarela eram apresentadas aleatoriamente e eram reforçadas com fichas as respostas de tocar o estímulo de comparação igual ao estímulo modelo quando a luz amarela estivesse acesa e as respostas de tocar o estímulo de comparação diferente do estímulo modelo quando a luz vermelha estivesse acesa. Esta fase era encerrada quando um de dois critérios fosse atingido, o que ocorresse primeiro: (a) a emissão de 10 respostas corretas consecutivas ou, (b) apresentação de 20 tentativas. A transição da Fase 3 para a Fase 4 também não era sinalizada; era marcada apenas pela mudança nas contingências de reforço.

A Fase 3 da Condição 3 diferia da Fase 3 das Condições 1 e 2 no seguinte aspecto: o experimentador dizia para o participante "muito bem" toda vez que as suas respostas estivessem de acordo com a instrução apresentada no início da Fase 2. Isto é, diferentemente das Condições 1 e 2, na Condição 3, as respostas de escolher o estímulo de comparação igual ao modelo na presença da luz vermelha e escolher o estímulo de comparação diferente do modelo na presença da luz amarela, durante a Fase 3, eram seguidas de reforço social. Assim, na Fase 3 das Condições 1 e 2, o seguir a instrução apresentada no início da Fase 2, não produzia fichas nem reforço social. Na Fase 3 da Condição 3, o seguir a instrução apresentada no início da Fase 2 , não produzia fichas, mas produzia reforço social.

Durante a Fase 4, as luzes vermelha e amarela eram apresentadas aleatoriamente e eram reforçadas com fichas as respostas de tocar o estímulo de comparação igual ao estímulo modelo quando a luz vermelha estivesse acesa e as respostas de tocar o estímulo de comparação diferente do estímulo modelo quando a luz amarela estivesse acesa. Esta fase era encerrada quando um de dois critérios fosse atingido, o que ocorresse primeiro: (a) a emissão de 10 respostas corretas consecutivas ou, (b) apresentação de 20 tentativas.

Nas três condições, quando uma resposta era reforçada com fichas, era reforçada em esquema de reforço contínuo (CRF). Em todas as fases, quando uma luz estivesse acesa a outra estava apagada. Cada participante era exposto a uma única sessão que era encerrada quando o participante atingisse o critério de encerramento da Fase 4, ou se o participante não atingisse o critério de desempenho para o encerramento da Fase 1. Ao término da sessão a criança era conduzida à lojinha e trocava as suas fichas por brinquedos e / ou guloseimas. Depois de encerrada a sessão, um observador independente comparava o registro feito pelo experimentador com o registro feito pela filmadora. Caso houvesse $100 \%$ de concordância entre os registros, os dados do participante eram considerados para análise; caso contrário, eram descartados. No presente estudo, nenhum dos dados coletados foi descar tado por essa ou qualquer outra razão.

Em síntese, nas três condições, a Fase 1 era iniciada com a apresentação de uma instrução mínima, a Fase 2 com a apresentação da instrução correspondente às contingências e as Fases 3 e 4 com a mudança nas contingências programadas. As condições diferiam nas Fases 1 e 3. Na Fase 1 da Condição 1, as respostas não eram reforçadas, enquanto na Fase 1 das Condições 2 e 3, as respostas corretas eram reforçadas diferencialmente com fichas. Na Fase 3 das Condições 1 e 2 , o seguimento de instrução não produzia fichas, nem reforço social. Na Fase 3 da Condição 3, o seguimento de instrução também não produzia fichas, mas produzia reforço social. Assim, as comparações entre fases, dentro de uma mesma condição, permitiam avaliar o controle por regras e o controle por contingências e as comparações entre condições permitiam avaliar, tanto os efeitos da história de controle por esquema de reforço contínuo (Condições 1 e 2), quanto a competição entre os efeitos dessa história e os efeitos do reforço social (Condições 2 e 3) sobre o comportamento de seguir regra exposto à mudança nas contingências programadas.

\section{Resultados}

\section{Condição 1}

A Tabela 2 mostra o número de respostas emitidas pelos Participantes P11, P12, P13 e P14 durante a Fase 1 da Condição 1. Observa-se que nenhum destes quatro participantes respondeu diferencialmente na presença das duas luzes. Três participantes (P11, P13 e P14) apontaram para o estímulo de comparação igual ao estímulo modelo em todas as tentativas; isto ocorreu três vezes na presença da luz vermelha e três vezes na presença da luz amarela, e um participante (P12) apontou duas vezes para o estímulo de comparação igual ao modelo e uma vez para o diferente do modelo tanto na presença da luz vermelha quanto na presença da luz amarela.

Tabela 2

Número de Respostas de Apontar Emitidas pelos Participantes da Condição 1 Durante a Fase 1

\begin{tabular}{lcccc}
\hline Participantes & \multicolumn{2}{c}{ Luz Vermelha } & \multicolumn{2}{c}{ Luz Amarela } \\
\hline & Igual & Diferente & Igual & Diferente \\
\cline { 2 - 5 } P11 & 3 & 0 & 3 & 0 \\
P12 & 2 & 1 & 2 & 1 \\
P13 & 3 & 0 & 3 & 0 \\
P14 & 3 & 0 & 3 & 0 \\
\hline
\end{tabular}

A Figura 1 mostra a freqüência acumulada de respostas corretas e incorretas emitidas pelos participantes (P11, P12, P13 e P14) da Condição 1, durante as Fases 2, 3 e 4. Observa-se na Fase 2 , quando a instrução correspondente foi introduzida, que estes quatro participantes responderam corretamente em todas as tentativas, emitindo as respostas especificadas por esta instrução. Ou seja, apontaram para o estímulo de comparação igual ao modelo na presença da luz vermelha e para o estímulo de comparação diferente do estímulo modelo na presença da luz amarela. 
Monteles, K.C., Paracampo, C.C.P., \& Albuquerque, L.C. Efeitos de uma História de Reforço Contínuo e de Conseqüências Sociais Sobre o Seguir Regras.
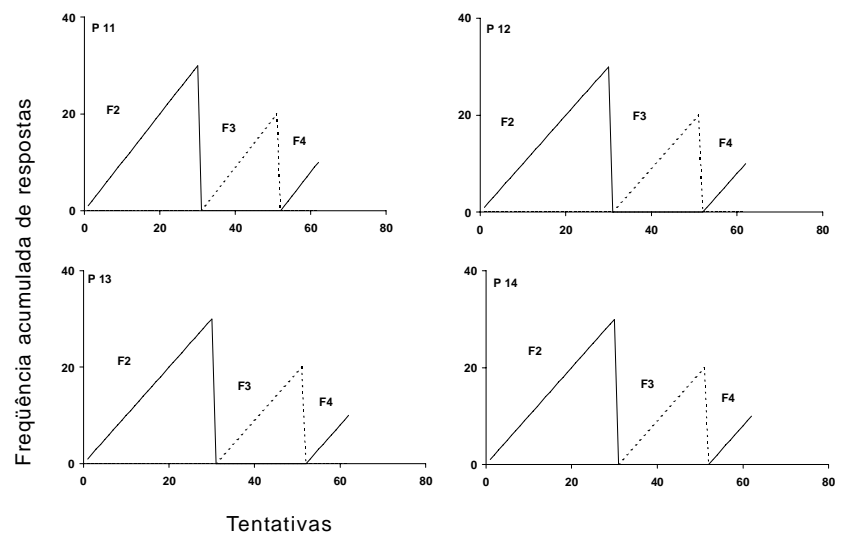

Figura 1. Freqüência acumulada de respostas corretas (linha sólida) e incorretas (linha tracejada), para cada participante $(\mathrm{P})$ da Condição 1, durante as Fases (F) 2, 3 e 4. Quebras na curva acumulada indicam mudanças de fase.

Na Fase 3, quando as contingências foram alteradas, estes quatro participantes (P11, P12, P13 e P14) continuaram seguindo a instrução apresentada no início da Fase 2, durante as 20 tentativas da Fase 3. Portanto, seus desempenhos tornaram-se incorretos nessa fase.

Na Fase 4, com o retorno às contingências em vigor na Fase 2, as respostas destes quatro participantes voltaram a se tornar corretas.

\section{Condição 2}

A Figura 2 mostra a freqüência acumulada de respostas corretas e incorretas emitidas pelos Participantes $\mathrm{P}_{21}$, $\mathrm{P}_{22}$, $\mathrm{P}_{23}, \mathrm{P}_{24}, \mathrm{P}_{25}$, $\mathrm{P}_{2} 6$ e $\mathrm{P}_{27}$ da Condição 2, durante as fases a que foram expostos. Pode-se observar que, na Fase 1, quatro participantes ( $\mathrm{P}_{21}, \mathrm{P}_{22}, \mathrm{P}_{23}$ e $\left.\mathrm{P}_{24}\right)$ atingiram o critério de desempenho para o encerramento dessa fase, ou seja, emitiram 10 respostas corretas consecutivas na presença das luzes vermelha e amarela quando elas passaram a ser apresentadas aleatoriamente e, deste modo, foram expostos às Fases 2, 3 e 4. Os outros três participantes ( $\mathrm{P}_{25}$, $\mathrm{P}_{26}$, e $\mathrm{P}_{27}$ ), mesmo sendo expostos a 100 tentativas, não atingiram esse critério de desempenho para o encerramento da Fase 1 e, portanto, não foram expostos às demais fases.
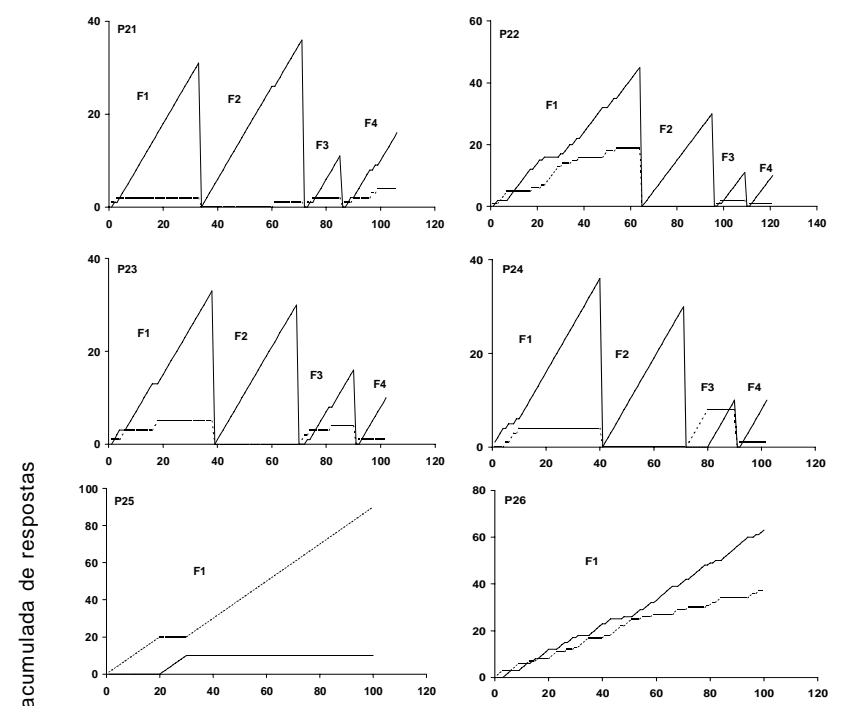

눈

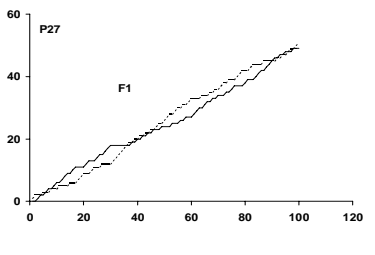

Tentativas

Figura 2. Freqüência acumulada de respostas corretas (linha sólida) e incorretas (linha tracejada), para cada participante $(\mathrm{P})$ da Condição 2, durante cada fase $(\mathrm{F})$ experimental. Quebras na curva acumulada indicam mudanças de fase.

Na Fase 2, quando a instrução correspondente foi apresentada, os Participantes $\mathrm{P}_{21}, \mathrm{P}_{22}, \mathrm{P}_{23}$ e $\mathrm{P}_{24}$ iniciaram esta fase seguindo esta instrução e continuaram seguindo instrução até o final dessa fase. O Participante $\mathrm{P}_{21}$ foi o único que emitiu uma resposta incorreta, na $24^{\mathrm{a}}$ tentativa dessa fase.

Na Fase 3, com a mudança nas contingências de reforço programadas, os Participantes $\mathrm{P}_{21}$, $\mathrm{P}_{22}$, $\mathrm{P}_{23}$ e $\mathrm{P}_{24}$ inicialmente persistiram respondendo de acordo com a instrução apresentada no início da Fase 2, mas a partir da $4^{\mathrm{a}}$, $4^{\mathrm{a}}, 13^{\mathrm{a}}$ e $9^{\mathrm{a}}$ tentativas, respectivamente, estes 4 participantes deixaram de seguir a instrução e passaram a responder corretamente, isto é, de acordo com as contingências de reforço em vigor na Fase 3.

$\mathrm{Na}$ Fase 4, com o retorno às contingências em vigor na Fase 2, os Participantes $\mathrm{P}_{21}$, $\mathrm{P}_{22}, \mathrm{P}_{23}$ e $\mathrm{P}_{24}$ novamente mudaram os seus desempenhos acompanhando as mudanças nas contingências de reforço e, assim, passaram a responder corretamente.

\section{Condição 3}

A Figura 3 mostra a freqüência acumulada de respostas corretas e incorretas emitidas pelos Participantes P31, P32, P33, P34, P35, P36 e P37 da Condição 3, durante as fases a que foram expostos. Pode-se observar que, na Fase 1, 4 participantes (P31, P32, P33 e P34) atingiram o critério de desempenho para o encerramento dessa fase e foram expostos às Fases 2, 3 e 4. Os outros 3 participantes (P35, 
P36 e P37), mesmo sendo expostos a 100 tentativas, não atingiram o critério de desempenho para o encerramento da Fase 1 e, portanto, não foram expostos às demais fases.
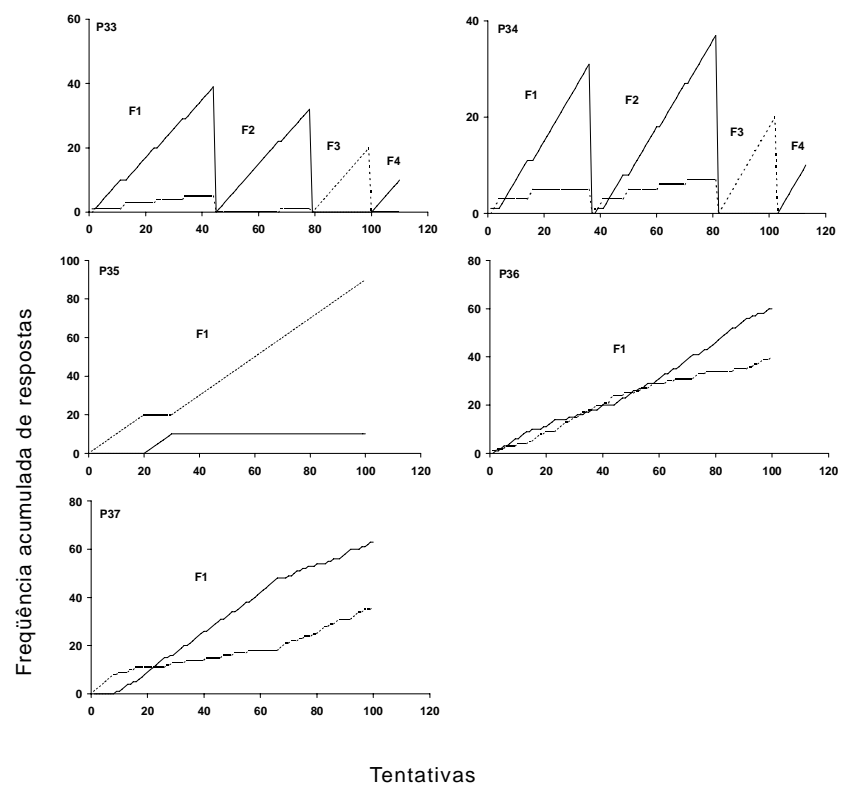

Figura 3. Freqüência acumulada de respostas corretas (linha sólida) e incorretas (linha tracejada), para cada participante $(\mathrm{P})$ da Condição 3 , durante cada fase $(\mathrm{F})$ experimental. Quebras na curva acumulada indicam mudanças de fase.

Na Fase 2, com a introdução da instrução correspondente, os Participantes P31, P32 e P33 imediatamente passaram a responder tal como especificado por esta instrução e, exceto em duas tentativas $\left(18^{\mathrm{a}}\right.$ e $23^{\mathrm{a}}$ tentativas, quando os Participantes P32 e P33, respectivamente, responderam incorretamente) continuaram seguindo a instrução até o final dessa fase. O Participante P34 foi o único que iniciou a Fase 2 apresentando um desempenho diferente do descrito na instrução; este participante não seguiu a instrução na $1^{\mathrm{a}}, 3^{\mathrm{a}}, 4^{\mathrm{a}}, 12^{\mathrm{a}}, 13^{\mathrm{a}}, 24^{\mathrm{a}}$ e $34^{\mathrm{a}}$ tentativas dessa fase. A partir da $35^{\mathrm{a}}$ tentativa, passou a responder de acordo com a instrução, sem apresentar erros.

$\mathrm{Na}$ Fase 3, quando as contingências mudaram, isto é, quando o responder de acordo com a instrução apresentada no início da Fase 2 deixou de produzir fichas e foi introduzida a conseqüência social ("Muito bem”) contingente a este responder, os Participantes P31, P32, P33 e P34, continuaram seguindo a instrução durante as 20 tentativas dessa fase e, deste modo, suas respostas tornaram-se incorretas.

$\mathrm{Na}$ Fase 4, com o retorno às contingências em vigor na Fase 2, as respostas dos Participantes P31, P32, P33 e P34 novamente se tornaram corretas.

\section{Discussão}

Os resultados da Condição 1 do presente estudo, mostrando que os 4 participantes (P11, P12, P13 e P14) dessa condição continuaram emitindo o comportamento de se- guir regra na Fase 3, quando este comportamento deixou de produzir as conseqüências especificadas na regra após a mudança nas contingências, fornecem evidências empíricas adicionais de que quando um responder é inicialmente estabelecido por regras ele tende a ficar insensível às mudanças nas contingências de reforço (Matthews et al., 1977; Shimoff et al., 1981; Paracampo et al., 2001). Já os resultados da Condição 2, mostrando que os Participantes $\mathrm{P}_{21}$, $\mathrm{P}_{22}$, $\mathrm{P}_{23}$ e $\mathrm{P} 24$ deixaram de emitir o comportamento de seguir regra na Fase 3, quando este comportamento deixou de produzir as conseqüências especificadas na regra após a mudança nas contingências, apóiam a proposição de que o comportamento de seguir regra discrepante das contingências tende a deixar de ocorrer quando o ouvinte é exposto a uma história de controle por esquema de reforço contínuo, antes de ser exposto à regra (L. C. Albuquerque et al., 2006). Contudo, os resultados da Condição 3, mostrando que os Participantes P31, P32 e P33 continuaram emitindo o comportamento de seguir regra na Fase 3, quando, após a mudança nas contingências, este comportamento deixou de produzir as conseqüências especificadas na regra, mas passou a produzir reforço social, sugerem que, nem sempre, a construção de uma história de reforço contínuo antes de o ouvinte ser exposto a uma regra é uma condição suficiente para impedir que uma regra, que se torna discrepante das contingências por ela descritas, exerça controle sobre o comportamento por ela especificado. Esta análise também pode ser aplicada ao desempenho do Participante P34, na Fase 3, que, diferente dos Participantes P31, P32 e P33, teve o comportamento estabelecido, possivelmente, pela interação entre a regra e as contingências no início da Fase 2.

Em outras palavras, os resultados das Condições 1 e 2, juntos, apóiam a proposição de que o comportamento de seguir regra, que se torna discrepante das contingências por ela descritas, tende a deixar de ocorrer quando o ouvinte é exposto a uma história de controle por esquema de reforço contínuo antes de ser exposto à regra (L. C. Albuquerque et al., 2006). Os resultados das Condições 2 e 3, entretanto, limitam a generalidade dessa proposição. Os resultados dessas duas últimas condições sugerem que o comportamento de seguir regra que produz reforço social tende a ser mantido, mesmo quando, antes de o ouvinte ser exposto à regra, é estabelecido um comportamento alternativo ao especificado pela regra, por meio de reforço diferencial em esquema de reforço contínuo, e o comportamento de seguir regra não produz as conseqüências por ela especificadas. Ou seja, sob estas condições, o controle pelas conseqüências sociais tende a impedir o controle pela história de reforço contínuo sobre o comportamento de seguir regra que não produz as conseqüências por ela especificadas. Os resultados do presente estudo sugerem, portanto, que a manutenção do comportamento de seguir regra pode depender, não apenas das condições que o antecedem, mas também do tipo de conseqüência por ele contatada.

Esta análise é consistente com o argumento de que o comportamento de seguir regras depende, em parte, do 
tipo de conseqüência por ele produzida (N. M. A. Albuquerque et al., 2004; Cerutti, 1989; Galizio, 1979; Paracampo \& L. C. Albuquerque, 2004). Além disso, é consistente com a proposição de que «o seguimento de regras depende mais da combinação entre o conjunto de condições favoráveis e o conjunto de condições não favoráveis à sua manutenção do que de uma ou outra dessas condições, isoladamente» (L. C. Albuquerque et al., 2003, p. 119). Analisando os presentes dados, de acordo com esta última proposição, pode-se sugerir que nas três condições do presente estudo os participantes foram expostos a condições que favoreciam tanto ao seguimento (como a presença do experimentador na situação experimental), quanto ao não-seguimento de regras (como o contato mantido pelo seguimento da regra com as conseqüências que contradiziam a própria regra). Mas, como na Condição 1 os participantes não foram expostos a uma história de controle por esquema de reforço contínuo antes da introdução da regra, enquanto na Condição 2 os participantes foram expostos a tal história, pode-se sugerir que, em relação à Condição 1 , os participantes da Condição 2 foram expostos a um número maior de condições favoráveis ao não-seguimento de regras. Do mesmo modo, como na Condição 2 o seguimento de regra não foi seguido de reforço social, enquanto na Condição 3 o seguimento de regra foi seguido por este tipo de conseqüência, pode-se sugerir que, em relação à Condição 2, os participantes da Condição 3 foram expostos a um número maior de condições favoráveis ao seguimento de regras.

É possível que, na Condição 2, a história de controle por esquema de reforço contínuo, construída antes de os participantes serem expostos à regra, tenha favorecido o não-seguimento de regra, porque essa historia estabeleceu um comportamento alternativo ao especificado pela regra e, deste modo, facilitou a discriminação da discrepância entre as conseqüências descritas na regra e as conseqüências produzidas pelo seguimento da regra após a mudança nas contingências (Baron \& Galizio, 1983; Cerutti, 1989, 1991). Ou seja, essa história pode ter contribuído para que o comportamento de seguir regra variasse no momento da mudança nas contingências (Le Francois et al., 1988; Joyce \& Chase, 1990; Chase \& Danforth, 1991). Um problema, no entanto, para esta suposição, é porque essa história também não exerceu essa função na Fase 3 da Condição 3. Uma possibilidade seria dizer que o reforço social dificultou a discriminação da discrepância entre as conseqüências descritas na regra (a produção de fichas) e as conseqüências produzidas pelo seguimento da regra após a mudança nas contingências (a não produção de fichas). Uma outra possibilidade seria dizer que a história de controle por esquema de reforço contínuo favoreceu a sensibilidade do seguimento subseqüente de regras às contingências na Fase 3 da Condição 2, mas não exerceu esta função na Fase 3 da Condição 3 , porque a emissão do comportamento alternativo ao especificado pela regra, estabelecido por essa história, envolvia baixo custo de resposta na Fase 3 da Condição 2 e alto custo de reposta na Fase 3 da Condição 3. Ou seja, na Fase
3 dessa última condição, o não-seguimento da regra implicava, mais evidentemente, em não fazer o que o experimentador havia dito que era para fazer, porque o experimentador também dizia «muito bem» toda vez que o participante fazia o que ele havia dito para fazer (L. C. Albuquerque et al., 2004; L. C. Albuquerque et al., 2006).

Esta análise sugere, portanto, que a apresentação do reforço social favoreceu o seguimento de regra. Talvez isto tenha ocorrido, porque essa conseqüência funcionou como um exemplo da classe de conseqüências sociais a que crianças geralmente são expostas quando fazem alguma coisa considerada "correta" nas suas interações com adultos. Em outras palavras, é possível que o seguimento de regra tenha sido mantido na Fase 3 da Condição 3, devido a uma história conseqüências mediadas socialmente para o responder de acordo com regras (Hayes et al., 1986), ou devido a uma história de exposição a regras e contingências para o seguimento e para o não-seguimento de regras em situações sociais. Situações em que membros da comunidade verbal estabelecem que o comportamento mais adaptativo é o de seguir regras. Por esta visão, uma implicação dos resultados da Condição 3, seria dizer que quando o seguimento de regras, sob algumas condições, mostra-se pouco adaptativo a mudanças em algumas contingências, ele pode estar sendo bastante adaptativo a contingências sociais (L. C. Albuquerque, 2004).

Pesquisas futuras, no entanto, deveriam continuar investigando os efeitos isolados e combinados de condições antecedentes e conseqüentes à apresentação de uma regra ao ouvinte. Tais pesquisas poderiam contribuir para delimitar ainda mais as condições sob as quais o comportamento estabelecido por regras é mais ou é menos provável de ser mantido. Por exemplo, pesquisas futuras poderiam investigar a competição entre os efeitos de conseqüências sociais, que os resultados do presente estudo mostraram que favorecem a manutenção do comportamento de seguir regras, com os efeitos de outros tipos de conseqüências, como perda de reforçadores, que os resultados de outros estudos (Galizio, 1979; N. M. A. Albuquerque et al., 2004; Paracampo \& L. C. Albuquerque, 2004) mostraram que favorecem a não manutenção desse comportamento.

\section{Referências}

Albuquerque, L. C. (2004). A cultura e a individualização das pessoas [Resumo]. In Programa de Pós-Graduação em Teoria e Pesquisa do Comportamento (Ed.), Anais, VII Semana Científica do Laboratório de Psicologia da UFPA (p. 3-4). Belém, PA: PPGTPC.

Albuquerque, L. C., Matos, M. A., de Souza, D. G., \& Paracampo, C. C. P. (2004). Investigação do controle por regras e do controle por histórias de reforço sobre o comportamento humano. Psicologia: Reflexão e Crítica, 17, 395-412.

Albuquerque, L. C., Reis, A. A., \& Paracampo, C. C. P. (2006). Efeitos de uma história de reforço contínuo sobre o seguimento de regras. Acta Comportamentalia, 14, 47-75.

Albuquerque, L. C., de Souza, D. G., Matos, M. A., \& Paracampo, C. C. P. (2003). Análise dos efeitos de histórias experimentais sobre o seguimento subsequiente de regras. Acta Comportamentalia, 11, 87-126. 
Albuquerque, N. M. A., Paracampo, C. C. P., \& Albuquerque, L C. (2004). Análise do papel de variáveis sociais e de consequiências programadas no seguimento de instruções. Psicologia, Reflexão e Crítica, 17, 3 1-42.

Baron, A., \& Galizio, M. (1983). Instructional control of human operant behavior. The Psychological Record, 33, 495-520.

Catania, A. C. (1998). Learning. Hillsdale, NJ: Prentice Hall.

Cerutti, D. T. (1989). Discrimination theory of rule-governed behavior. Journal of the Experimental Analysis of Behavior, 51, 259-276.

Cerutti, D. T. (1991). Discriminative versus reinforcing properties of schedules as determinants of schedule insensitivity in humans. The Psychological Record, 41, 51-67.

Chase, P. N., \& Danforth, J. S. (1991). The role of rules in concept learning. In L. J. Hayes \& P. N. Chase (Eds.), Dialogues on verbal behavior (pp. 205-225). Hillsdale, NJ: Lawrence Erlbaum.

Galizio, M. (1979). Contincency-shaped and rule-governed behavior: Instructional control of human loss avoidance. Journal of Experimental Analysis of Behavior, 31, 53-70.

Hayes, S. C., Brownstein, A. J., Zettle, R. D., Rosenfarb, I., \& Korn, Z. (1986). Rule governed behavior and sensitivity to changing consequences of responding. Journal of the Experimental Analysis of Behavior, 45, 237-257.

Hayes, S. C., Zettle, R. D., \& Rosenfarb, I. (1989). Rule-following. In S. C. Hayes (Ed.), Rule governed behavior: Cognition, contingencies, and instructional control (p. 191-218). New York: Plenum.

Joyce, J. H., \& Chase, P. N. (1990). Effects of response variability on the sensivity of rule-governed behavior. Journal of the Experimental Analysis of Behavior, 54, 251-262.

Kaufman, A., Baron, A., \& Koop, R. E. (1966). Some effects of instructions on human operant behavior. Psychonomic Monograpg Supplements, 1, 243-250.

LeFrancois, J. R., Chase, P. N., \& Joyce, J. (1988). The effects of variety of instrucions on human fixed-interval perfomance. Journal of the Experimental Analysis of Behavior, 49, 383-393.

Malott, R. M. (1989). Achievement of evasive goals. In S. C. Hayes (Ed.), Rule governed behavior: Cognition, contingencies, and instructional control (pp. 153-190). New York: Plenum.

Matthews, B. A., Shimoff, E., \& Catania, A. C. (1977). Unistructed human responding: Sensitivity to ratio and interval contingencies. Journal of the Experimental Analysis of Behavior, 27, 453-467.

Paracampo, C. C. P., \& Albuquerque, L. C. (2004). Análise do papel das consequiências programadas no seguimento de regras. Interação em Psicologia, 8, 237-245.

Paracampo, C. C. P., de Souza, D. G., Matos, M. A., \& Albuquerque, L. C. (2001). Efeitos de mudança em contingências de reforço sobre o comportamento verbal e não verbal. Acta Comportamentalia, 9, 31-55.

Santos, J. G. W., Paracampo, C. C. P., \& Albuquerque, L. C. (2004). Análise dos efeitos de histórias de variação comportamental sobre o seguimento de regras. Psicologia: Reflexão e Crítica, $17,413-425$.

Shimoff, E., Catania, A. C., \& Matthews, B. A. (1981). Uninstructed human responding: Sensitivity of low-rate performance to schedule contingencies. Journal of the Experimental Analysis of Behavior, 36, 207-220.

Skinner, B. F. (1969). Contingencies of reiforcement: $A$ theoretical analysis. New York: Appleton-Century-Crofts.

Torgrud, L. J., \& Holborn, S. W. (1990). The effects of verbal performance descriptions on nonverbal operant responding. Journal of the Experimental Analysis of Behavior, 54, 273-291.
Weiner, H., (1970). Instructional Control of human operant responding during extinction following fixed-ratio conditioning. Journal of the Analysis Experimental of Behavior, 13, 391-394.

Zettle, R. D., \& Hayes, S. C. (1982). Rule-governed behavior: A potential theoretical framework for cognitive-behavior therapy. In P. C. Kendall (Ed.), Advances in cognitive-behavioral research and therapy (p. 73-118). New York: Academic Press.
Recebido: 27/09/2004 $1^{a}$ revisão: 08/12/2004 $2^{a}$ revisão: $16 / 06 / 2005$ Aceite final: 16/09/2005 